\title{
Composite endpoints in COPD: clinically important deterioration in the UPLIFT trial
}

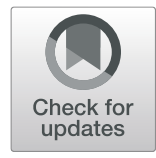

\author{
Klaus F. Rabe ${ }^{1,2^{*}}$, David M. G. Halpin ${ }^{3}$, MeiLan K. Han ${ }^{4}$, Marc Miravitlles ${ }^{5}$, Dave Singh ${ }^{6}$, Lars Grönke7, \\ Florian Voß ${ }^{8}$ and Fernando J. Martinez ${ }^{9}$
}

\begin{abstract}
Background: Assessments of lung function, exacerbations and health status are common measures of chronic obstructive pulmonary disease (COPD) progression and treatment response in clinical trials. We hypothesised that a composite endpoint could more holistically assess clinically important deterioration (CID) in a COPD clinical trial setting.

Methods: A composite endpoint was tested in a post hoc analysis of 5652 patients with Global Initiative for Chronic Obstructive Lung Disease (GOLD) 2-4 COPD from the 4-year UPLIFT study. Patients received tiotropium $18 \mu \mathrm{g}$ or placebo.

Results: The composite endpoint included time to first confirmed decrease in trough forced expiratory volume in $1 \mathrm{~s}\left(\mathrm{FEV}_{1}\right) \geq 100 \mathrm{~mL}$, confirmed increase in St. George's Respiratory Questionnaire (SGRQ) total score $\geq 4$ units, or moderate/severe exacerbation. Most patients (> 80\%) experienced CID, with similar incidence among GOLD subgroups. Most confirmed trough FEV 1 (74.6-81.6\%) and SGRQ (72.3-78.1\%) deteriorations were sustained across the study and in all GOLD subgroups. Patients with CID more frequently experienced subsequent exacerbation (hazard ratio $[\mathrm{HR}] 1.79 ; 95 \%$ confidence interval $[\mathrm{Cl}] 1.67,1.92)$ or death $(\mathrm{HR} 1.21 ; 95 \% \mathrm{Cl} 1.06,1.39)$ by Month 6 . CID was responsive to bronchodilator treatment.
\end{abstract}

Conclusions: Composite endpoints provide additional information on COPD progression and treatment effects in clinical trials.

Trial registration: ClinicalTrials.gov NCT00144339.

Keywords: Tiotropium, Lung function, Exacerbations

\section{Background}

Chronic obstructive pulmonary disease (COPD) is a chronic, progressive, heterogeneous disease. The manifestation of disease progression varies over time and between patients. Despite this, most clinical trials conducted in COPD typically focus on a single primary outcome such

\footnotetext{
* Correspondence: k.f.rabe@lungenclinic.de

${ }^{1}$ Member of the German Center for Lung Research (DZL), LungClinic Grosshansdorf, Wöhrendamm 80, 22927 Grosshansdorf, Germany

${ }^{2}$ Member of the German Center for Lung Research (DZL), Christian Albrechts University Kiel, Kiel, Germany

Full list of author information is available at the end of the article
}

as forced expiratory volume in $1 \mathrm{~s}\left(\mathrm{FEV}_{1}\right)$, exacerbation frequency or, less frequently, mortality.

The impact of interventions on disease progression has been measured by the annual rate of decline in $\mathrm{FEV}_{1}$ over several years [1]. However, there are limitations to this approach. Individuals with a slower rate of decline may dilute any observable treatment benefit in rapidly progressing subgroups. Moreover, individuals with a rapid decline may discontinue studies early, underestimating the true mean rate of decline in the control arm [2].

Primary analyses of clinical trials typically report group mean results, which can be insufficient to detect

(c) The Author(s). 2020 Open Access This article is licensed under a Creative Commons Attribution 4.0 International License, which permits use, sharing, adaptation, distribution and reproduction in any medium or format, as long as you give appropriate credit to the original author(s) and the source, provide a link to the Creative Commons licence, and indicate if changes were made. The images or other third party material in this article are included in the article's Creative Commons licence, unless indicated otherwise in a credit line to the material. If material is not included in the article's Creative Commons licence and your intended use is not permitted by statutory regulation or exceeds the permitted use, you will need to obtain permission directly from the copyright holder. To view a copy of this licence, visit http://creativecommons.org/licenses/by/4.0/ The Creative Commons Public Domain Dedication waiver (http://creativecommons.org/publicdomain/zero/1.0/) applies to the data made available in this article, unless otherwise stated in a credit line to the data. 
clinically important changes at the individual patient level. Furthermore, the focus on only one dimension of COPD may misrepresent real improvements that are meaningful to patients.

Measuring clinically important deterioration (CID) in terms of the most impactful events at the individual patient level might provide a significant benefit in studying the progression and effects of COPD in clinical trials. The three events included in this composite endpoint trough $\mathrm{FEV}_{1}$, St. George's Respiratory Questionnaire (SGRQ) score and moderate/severe exacerbation - have been previously used by Singh et al. [3], Anzueto et al. [4] and Greulich et al. [5], and were selected because they are commonly used in clinical trials and are known to have an impact on patients with COPD.

To explore the composite endpoint of CID further, we used a post hoc analysis of the 4-year UPLIFT study. The objectives of this analysis were to test the validity of CID when only including $\mathrm{FEV}_{1}$ and SGRQ events that were confirmed at a subsequent visit, to prove that CID predicts future outcomes, and to explore other elements of CID.

\section{Methods}

This post hoc analysis assessed time to first CID as time to the first occurrence of at least one of the following: decrease in trough $\mathrm{FEV}_{1}$ from baseline $\geq 100 \mathrm{~mL}$, increase in SGRQ total score from baseline $\geq 4$ units or moderate/severe exacerbation (the same components as suggested by Singh et al. [3]). Changes in $\mathrm{FEV}_{1}$ and SGRQ score were always calculated from baseline. Changes in $\mathrm{FEV}_{1}$ were assessed using pre-bronchodilation values, in line with previous studies assessing CID [6-8] and reflecting realworld clinical practice for $\mathrm{FEV}_{1}$ monitoring. A decrease in trough $\mathrm{FEV}_{1} \geq 100 \mathrm{~mL}$ is considered to be the minimum clinically important change perceived by patients $[9,10]$ and is within the defined range suggested by the American Thoracic Society/European Respiratory Society task force [11], whereas an increase in SGRQ total score $\geq 4$ units is considered the minimum clinically important change in quality of life [12].

Unlike for the composite endpoint published by Singh et al. [3], we only included confirmed $\mathrm{FEV}_{1}$ and SGRQ deteriorations, i.e. events that were present during at least two consecutive assessments (5 or 6 months apart). This excluded short-term fluctuations in the disease, which could provide an unreliable indication of CID. If no further assessment was available, but the patient discontinued study medication or died, the event was also considered as confirmed. Confirmed events were not required for exacerbations of COPD.

We have used the term "sustained" to refer to deteriorations that were then maintained at almost every subsequent visit.

\section{Study design}

Study design details have been previously reported [13] and are briefly summarised below. UPLIFT (ClinicalTrials.gov: NCT00144339) was a 4-year, randomised, double-blind, parallel-group study comparing tiotropium $18 \mu \mathrm{g}$, administered once daily via the HandiHaler ${ }^{\circ}$, with matching placebo [14]. The UPLIFT study was conducted in 37 countries [14]. Patients were aged $\geq 40$ years, with a smoking history of $\geq 10$ pack-years and moderate-to-very severe COPD (Global Initiative for Chronic Obstructive Lung Disease [GOLD] 2-4 [15]). For further details, see the Supplementary Methods. The protocol was approved by the ethics committee at each centre, and all patients provided written, informed consent.

Spirometric testing was performed at randomisation, at the Day 30 visit and at visits every 6 months up to Month 48. SGRQ was assessed at randomisation and every 6 months up to Month 48. Exacerbations and associated hospital admissions were recorded on case report forms at every visit. The two primary endpoints were pre- and post-bronchodilation yearly rate of decline in mean $\mathrm{FEV}_{1}$.

\section{Statistical analysis}

For time-to-event endpoints, hazard ratios (HRs), 95\% confidence intervals (CIs) and $P$ values were calculated using a Cox proportional hazards model. Patients without CID events were censored at the treatment stop date.

To assess the association of CID with future outcomes, patients experiencing a CID event within the first 6 months were compared with those not experiencing the event. For this analysis, the time to first moderate/severe exacerbation was calculated from Month 6 (180 days) to the first subsequent event or treatment discontinuation. Time to death was calculated from Month 6 (180 days) to the date of death or the end of the vital status followup (Day 1470).

\section{Results}

Patient dispositions have been reported previously [14]. Overall, 5652 patients received treatment (2811 tiotropium; 2841 placebo) and had baseline measurements for both $\mathrm{FEV}_{1}$ and SGRQ. GOLD stage at baseline (based on post-bronchodilator $\mathrm{FEV}_{1}$ ) was available for $5589 \mathrm{pa}-$ tients (GOLD 2: 1293 placebo, 1310 tiotropium; GOLD 3: 1266 placebo, 1239 tiotropium; GOLD 4: 250 placebo, 231 tiotropium).

\section{Incidence of CID}

Most patients in the total population (83.9\%) experienced at least one CID during the study (Table 1). Exacerbations were more frequent than $\mathrm{FEV}_{1}$ or SGRQ decline (Table 1). 
Table 1 Incidence of CID and risk of first CID occurrence in total population and by GOLD stage

\begin{tabular}{|c|c|c|c|c|}
\hline & Overall population & GOLD 2 & GOLD 3 & GOLD 4 \\
\hline \multicolumn{5}{|l|}{ Total UPLIFT population (placebo and tiotropium combined) } \\
\hline Number of patients, n (\%) & $5652(100.0)$ & $2603(100.0)$ & $2505(100.0)$ & $481(100.0)$ \\
\hline $\begin{array}{l}\text { At least one of } \mathrm{SGRQ} \text { deterioration (decrease of } \geq 4 \text { units), } \\
\text { trough } \mathrm{FEV}{ }_{1} \text { decline } \geq 100 \mathrm{~mL} \text { or moderate/severe exacerbation }\end{array}$ & $4741(83.9)$ & $2175(83.6)$ & $2127(84.9)$ & $388(80.7)$ \\
\hline Moderate/severe exacerbation & $3814(67.5)$ & $1615(62.0)$ & $1796(71.7)$ & $357(74.2)$ \\
\hline Trough FEV 1 decline $\geq 100 \mathrm{~mL}$ & $2503(44.3)$ & $1344(51.6)$ & $1031(41.2)$ & $100(20.8)$ \\
\hline SGRQ score increase $\geq 4$ units & $2339(41.4)$ & $1081(41.5)$ & $1054(42.1)$ & $178(37.0)$ \\
\hline
\end{tabular}

CID clinically important deterioration, FEV 1 forced expiratory volume in $1 \mathrm{~s}, G O L D$ Global Initiative for Chronic Obstructive Lung Disease, SGRQ St. George's

Respiratory Questionnaire

The contribution of exacerbations to the composite endpoint became more pronounced whereas the contribution of $\mathrm{FEV}_{1}$ became less pronounced as COPD severity (GOLD stage) increased in the total population (Table 1).

Time to first event for each component is shown in eFigure 1.

Overall, about half of patients experienced at least two of the three events qualifying as CID, whereas fewer patients experienced all three events (Fig. 1a). A similar proportion of patients in each GOLD group experienced at least two CID events (Fig. 1b-d). The incidence of all three CID events was also similar for GOLD 2 and 3 patients, whereas few GOLD 4 patients experienced all three CID events (Fig. 1b-d).

Overall, most confirmed events were sustained at subsequent visits. Confirmed trough $\mathrm{FEV}_{1}$ decline was sustained at 12-48 months after the initial event in 74.6$81.6 \%$ of patients (Table 2). Confirmed SGRQ deterioration was also sustained at 12-42 months after the initial event in $72.3-78.1 \%$ of patients (Table 2). This pattern was comparable with the GOLD subgroups (e-Table 1), although patient numbers were low for the GOLD 4 subgroup.

For unconfirmed events (reported at one timepoint), the proportion of patients whose $\mathrm{FEV}_{1}$ decline or SGRQ deterioration was sustained was lower: $51.6-71.9 \%$ of patients still had the $\mathrm{FEV}_{1}$ decline 6-48 months after first decline, and 52.5-65.5\% still had SGRQ deterioration (eTable 2).

In addition, in patients who had confirmed events, mean $\mathrm{FEV}_{1}$ remained at least $193 \mathrm{~mL}$ worse than baseline for the rest of the trial (Table 2). For unconfirmed events, mean $\mathrm{FEV}_{1}$ in patients with an event ranged from $95 \mathrm{~mL}$ worse than baseline at Month 6 to $142 \mathrm{~mL}$ worse than baseline at Month 24 and 213 $\mathrm{mL}$ at Month 48. In patients with SGRQ deterioration, mean increase was $>10$ units for the rest of the trial for confirmed events, but ranged from 4.7 to 8.3 units for unconfirmed events.

\section{Relative timing of events}

The pattern and timing of clinically relevant events was highly variable for individual patients. Of patients who experienced both confirmed FEV ${ }_{1}$ decline and SGRQ deterioration, it was unusual to experience both events at the same assessment (Table 3). The time from $\mathrm{FEV}_{1}$ decline to subsequent SGRQ deterioration was slightly longer than the time from SGRQ deterioration to subsequent $\mathrm{FEV}_{1}$ decline (Fig. 2).

For patients who experienced both $\mathrm{FEV}_{1}$ decline and SGRQ deterioration, those with less spirometric obstruction appeared more likely to experience confirmed $\mathrm{FEV}_{1}$ decline prior to confirmed SGRQ deterioration (GOLD 2: 50.1\%; GOLD 3: 41.6\%; GOLD 4: 37.0\%) (Table 3).

Exacerbations demonstrated a greater contribution to the composite endpoint in more severe patients. Patients with more severe COPD were more likely to experience an exacerbation prior to experiencing $\mathrm{FEV}_{1}$ decline or SGRQ deterioration (Table 3).

\section{Response to treatment}

The time to first CID event, and time to first occurrence of the individual components, was sensitive to therapeutic intervention (Table 4). Time to first CID, two CID events and all three CID events was longer with tiotropium than with placebo (Table 4 and Fig. 1a). This trend was observed in GOLD 2 and 3 subgroups, but less so with GOLD 4 patients (Fig. 1b-d).

\section{Risk of future exacerbations and death}

Patients who had CID events by Month 6 were more likely to experience a moderate or severe exacerbation (HR 1.79; 95\% CI 1.67, 1.92), a severe exacerbation (HR 1.67; $95 \%$ CI $1.49,1.86$ ) or death (HR 1.21; 95\% CI 1.06, 1.39) (Table 5). The increase in the risk of exacerbations was qualitatively similar for GOLD 2-4 subgroups (Table 5).

When the composite endpoint was broken down into its component events, the HRs for future exacerbations were smaller for $\mathrm{FEV}_{1}$ decline and SGRQ deterioration 


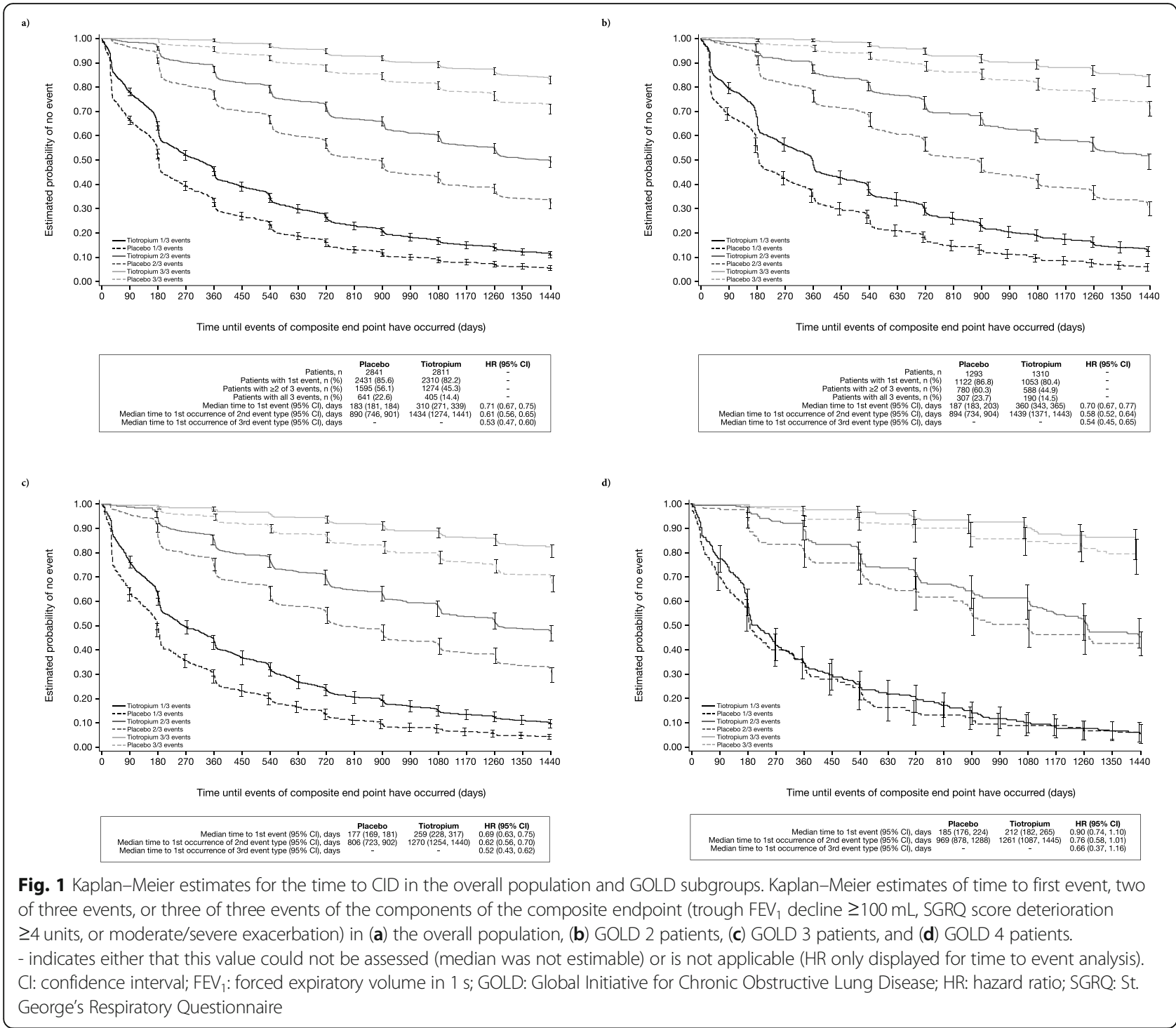

by Month 6 than for the composite endpoint in the overall population, and among GOLD 2 and GOLD 3 COPD patients (Table 5). Exacerbations within 6 months had higher HRs for any exacerbation and for severe exacerbations than the composite endpoint.

For unconfirmed events, the HRs for long-term outcomes were lower than for the sustained events (Table 5 and e-Table 3).

Investigating future events by CID status at Month 12 showed similar results (e-Table 4).

\section{Mortality analysis with CID}

Additional analyses using time to composite event or time to one of the component events as a time-varying covariate were performed. The HR for death for patients with a CID event versus patients without an event was 1.69 (95\% CI 1.42, 2.01) (e-Table 5).

Using a stepwise Cox regression model to adjust for important baseline predictors of mortality had little effect on the predictive performance of the composite (eTable 5). When all three components were included as separate predictors, all were associated with increased mortality risk (e-Table 5).

To validate these findings, the results in eTables 4, 6 and 7 are presented for the placebo and tiotropium arms separately. The HRs are slightly higher in the tiotropium arm, which may be related to the larger number of events in the placebo arm before Month 6. The results in e-Tables 6 and 7 are similar between arms and confirm the results in the total population. 
Table 2 Patients with $\mathrm{FEV}_{1}$ decline or SGRQ deterioration in the total population

\begin{tabular}{|c|c|c|c|c|c|c|c|c|}
\hline & \multirow{2}{*}{\multicolumn{8}{|c|}{$\begin{array}{l}\text { Patients with confirmed } \mathrm{FEV}_{1} \text { decline or SGRQ deterioration at time points after the initial decline } \\
\text { (available assessments) } \\
\text { Months after confirmed } \mathrm{FEV}_{1} \text { decline or SGRQ increase }\end{array}$}} \\
\hline & & & & & & & & \\
\hline & 6 & 12 & 18 & 24 & 30 & 36 & 42 & 48 \\
\hline \multicolumn{9}{|l|}{$\mathrm{FEV}_{1}$ decline } \\
\hline $\begin{array}{l}\text { No. of patients with } \\
\text { decline, } \mathrm{n}(\%)\end{array}$ & $\begin{array}{l}1924 / 1924 \\
(100)\end{array}$ & $\begin{array}{l}1239 / 1661 \\
(74.6)\end{array}$ & $\begin{array}{l}1091 / 1447 \\
(75.4)\end{array}$ & $\begin{array}{l}895 / 1199 \\
(74.6)\end{array}$ & $\begin{array}{l}754 / 966 \\
(78.1)\end{array}$ & $\begin{array}{l}604 / 755 \\
(80.0)\end{array}$ & $\begin{array}{l}419 / 549 \\
(76.3)\end{array}$ & $\begin{array}{l}280 / 343 \\
(81.6)\end{array}$ \\
\hline $\begin{array}{l}\text { Mean } \mathrm{FEV}_{1} \text { change } \\
\text { from baseline, } \\
\mathrm{mL} \text { (SD) }\end{array}$ & $-223(114)$ & $-193(176)$ & $-202(187)$ & $-214(195)$ & $-237(212)$ & $-256(224)$ & $-258(230)$ & $-280(224)$ \\
\hline $\begin{array}{l}\text { Median } \mathrm{FEV}_{1} \text { change from } \\
\text { baseline } \mathrm{mL}(\mathrm{min} \text {, max) }\end{array}$ & $\begin{array}{l}-190 \\
(-1090,-40)\end{array}$ & $\begin{array}{l}-180 \\
(-1240,850)\end{array}$ & $\begin{array}{l}-200 \\
(-1000,0.630)\end{array}$ & $\begin{array}{l}-210 \\
(-1070,0.740)\end{array}$ & $\begin{array}{l}-240 \\
(-1190,650)\end{array}$ & $\begin{array}{l}-240 \\
(-1200,490)\end{array}$ & $\begin{array}{l}-250 \\
(-980,460)\end{array}$ & $\begin{array}{l}-270 \\
(-920,670)\end{array}$ \\
\hline \multicolumn{9}{|l|}{ SGRQ deterioration } \\
\hline $\begin{array}{l}\text { No. of patients with } \\
\text { deterioration, } \\
\mathrm{n}(\%)\end{array}$ & $\begin{array}{l}1785 / 1785 \\
(100)\end{array}$ & $\begin{array}{l}1140 / 1510 \\
(75.5)\end{array}$ & $\begin{array}{l}941 / 1301 \\
(72.3)\end{array}$ & $\begin{array}{l}776 / 1067 \\
(72.7)\end{array}$ & $\begin{array}{l}629 / 843 \\
(74.6)\end{array}$ & $\begin{array}{l}462 / 617 \\
(74.9)\end{array}$ & $\begin{array}{l}303 / 388 \\
(78.1)\end{array}$ & \\
\hline $\begin{array}{l}\text { Mean SGRQ change from } \\
\text { baseline (SD) }\end{array}$ & $12.5(7.5)$ & $10.6(10.7)$ & $10.2(11.4)$ & $10.7(12.3)$ & $11.3(12.6)$ & $11.8(12.8)$ & $12.3(12.8)$ & \\
\hline $\begin{array}{l}\text { Median SGRQ score } \\
\text { change from baseline } \\
\text { (min, max) }\end{array}$ & $\begin{array}{l}10.5 \\
(4.0,53.1)\end{array}$ & $\begin{array}{l}9.5 \\
(-48.4,53.9)\end{array}$ & $\begin{array}{l}9.3 \\
(-44.2,67.8)\end{array}$ & $\begin{array}{l}10.2 \\
(-44.5,69.6)\end{array}$ & $\begin{array}{l}10.7 \\
(-36.6,54.6)\end{array}$ & $\begin{array}{l}10.9 \\
(-33.8,50.1)\end{array}$ & $\begin{array}{l}11.9 \\
(-29.8,47.3)\end{array}$ & \\
\hline
\end{tabular}

For patients with confirmed decline at Month 1, their assessments at Months 6, 12, 18, 24, 30, 36, 42 and 48 are used as time from first confirmed deterioration. Unscheduled visits were excluded for this analysis. Only patients with confirmed FEV ${ }_{1}$ decline or confirmed SGRQ deterioration and available assessments at each time point after the deterioration were included in the analysis

$F E V_{1}$ forced expiratory volume in $1 \mathrm{~s}$, SD standard deviation, SGRQ St. George's Respiratory Questionnaire

\section{Discussion}

Composite endpoints have only recently been introduced in post hoc analyses of COPD clinical trials $[3-6,16]$. Here, we conducted a post hoc analysis of the UPLIFT study. This analysis demonstrated the importance of using confirmed events in CID analysis and that CID predicts future outcomes. It also confirmed that the components of this composite endpoint behaved differently based on the baseline $\mathrm{FEV}_{1}$ of the individual patient. These data suggest that sustained decline in trough $\mathrm{FEV}_{1}$, sustained deterioration in SGRQ score of $\geq 4$ units and a moderate/severe exacerbation are appropriate components of a composite endpoint for the assessment of CID in

Table 3 Timing of FEV 1 decline and SGRQ deterioration in the overall population and GOLD subgroups

\begin{tabular}{|c|c|c|c|c|}
\hline & Overall & GOLD 2 & GOLD 3 & GOLD 4 \\
\hline Patients with both confirmed FEV 1 decline and confirmed SGRQ deterioration, n (\%) & $1344(100.0)$ & $698(100.0)$ & $575(100.0)$ & $54(100.0)$ \\
\hline On same assessment & $240(17.9)$ & $121(17.3)$ & $108(18.8)$ & $9(16.7)$ \\
\hline $\mathrm{FEV}_{1}$ decline before SGRQ deterioration & $620(46.1)$ & $350(50.1)$ & $239(41.6)$ & $20(37.0)$ \\
\hline SGRQ deterioration before $\mathrm{FEV}_{1}$ decline & $484(36.0)$ & $227(32.5)$ & $228(39.7)$ & $25(46.3)$ \\
\hline Moderate/severe exacerbation before $\mathrm{FEV}_{1}$ and $\mathrm{SGRQ}$ deterioration & $546(40.6)$ & $246(35.2)$ & $269(46.8)$ & $24(44.4)$ \\
\hline Patients with confirmed FEV 1 decline and no confirmed SGRQ deterioration, n (\%) & $1160(100.0)$ & $644(100.0)$ & $459(100.0)$ & $46(100.0)$ \\
\hline Moderate/severe exacerbation before $\mathrm{FEV}_{1}$ decline & $460(39.7)$ & $231(35.9)$ & $199(43.4)$ & $24(52.2)$ \\
\hline Unconfirmed SGRQ deterioration & $302(26.0)$ & $180(28.0)$ & $109(23.7)$ & $10(21.7)$ \\
\hline On same assessment as confirmed FEV 1 decline & $34(2.9)$ & $20(3.1)$ & $12(2.6)$ & $1(2.2)$ \\
\hline Before confirmed $\mathrm{FEV}_{1}$ decline & $116(10.0)$ & $72(11.2)$ & $36(7.8)$ & $7(15.2)$ \\
\hline Patients with confirmed SGRQ and no confirmed FEV 1 deterioration, n (\%) & $995(100.0)$ & $383(100.0)$ & $479(100.0)$ & $124(100.0)$ \\
\hline Moderate/severe exacerbation before SGRQ deterioration & $574(57.7)$ & $184(48.0)$ & $305(63.7)$ & $80(64.5)$ \\
\hline Unconfirmed $\mathrm{FEV}_{1}$ deterioration & $284(28.5)$ & $141(36.8)$ & $126(26.3)$ & $15(12.1)$ \\
\hline On same assessment as confirmed SGRQ deterioration & $50(5.0)$ & $23(6.0)$ & $24(5.0)$ & $3(2.4)$ \\
\hline Before confirmed SGRQ deterioration & $151(15.2)$ & $80(20.9)$ & $64(13.4)$ & $5(4.0)$ \\
\hline
\end{tabular}

Unscheduled visits were excluded for this analysis

$F E V_{1}$ forced expiratory volume in $1 \mathrm{~s}, G O L D$ Global Initiative for Chronic Obstructive Lung Disease, SGRQ St. George's Respiratory Questionnaire 


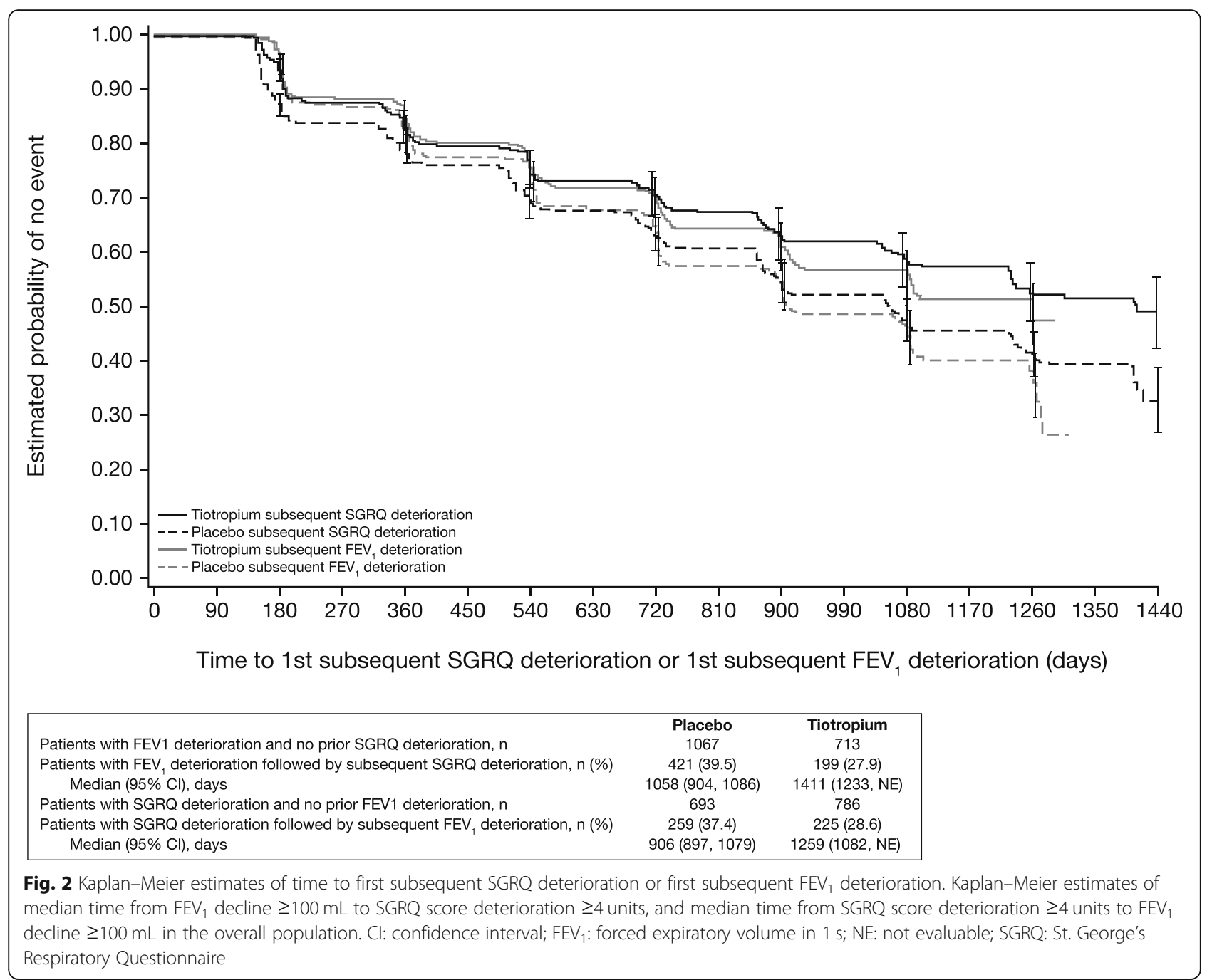

patients enrolled in COPD clinical trials. Earlier analyses of the UPLIFT trial have focused on exacerbations or a composite endpoint of the more severe events (exacerbations, respiratory failure, death and trial withdrawal due to worsening COPD), which do not provide an in-depth view of the impact of COPD on patient symptoms or quality of life $[16,17]$. In the current analysis we focus on a composite endpoint of validated clinically important criteria $\left(\mathrm{FEV}_{1}, \mathrm{SGRQ}\right.$ and exacerbations) to provide a more complete assessment of the impact on patients.

The individual components of the composite endpoint comprise characteristics of COPD that impact patient well-being, are clinically relevant events for the patient and predict future outcomes [15]. Although there are other parameters that could be included in such an endpoint, the components included are relatively easy to include in clinical trials and have established minimum clinically important differences.
Most deteriorations in $\mathrm{FEV}_{1}$ and SGRQ that were confirmed at a second visit were maintained for the rest of the 4-year UPLIFT study. Some publications of composite endpoints in COPD have not required confirmation at a subsequent visit $[3,16]$. We believe that counting only confirmed $\mathrm{FEV}_{1}$ and SGRQ deteriorations improves the reliability of the composite endpoint, as it excludes short-term variation and inconsistent measurements. This is supported by the low proportion of patients with unconfirmed events whose $\mathrm{FEV}_{1}$ or SGRQ deterioration is sustained at subsequent timepoints, and by the lower HRs for long-term outcomes with unconfirmed events compared with confirmed events.

Our analysis demonstrated that the components of the composite endpoint rarely occur at the same time in an individual patient. Most patients experience decline of trough $\mathrm{FEV}_{1}$, deterioration of SGRQ score and moderate/severe exacerbations on an individualised time scale. This supports the value of individual components in a 
Table 4 Treatment comparison of time to first CID in the overall population and by GOLD stage

\begin{tabular}{|c|c|c|c|c|}
\hline & \multicolumn{2}{|l|}{ Event, n (\%) } & \multicolumn{2}{|c|}{$\begin{array}{l}\text { Time to first event } \\
\text { treatment comparison } \\
\text { (tiotropium-placebo) }\end{array}$} \\
\hline & Tiotropium $18 \mu \mathrm{g}$ & Placebo & $\mathrm{HR}(95 \% \mathrm{Cl})$ & $P$ value \\
\hline Overall & $2811(100.0)$ & $2841(100.0)$ & & \\
\hline SGRQ deterioration, trough $\mathrm{FEV}_{1}$ decline $\geq 100 \mathrm{~mL}$, moderate/severe exacerbation & $2310(82.2)$ & $2431(85.6)$ & $0.71(0.67,0.75)$ & $<0.0001$ \\
\hline Moderate/severe exacerbation & $1884(67.0)$ & $1930(67.9)$ & $0.86(0.81,0.92)$ & $<0.0001$ \\
\hline Trough FEV 1 decline $\geq 100 \mathrm{~mL}$ & $1028(36.6)$ & $1475(51.9)$ & $0.53(0.49,0.58)$ & $<0.0001$ \\
\hline SGRQ score increase $\geq 4$ units & $1077(38.3)$ & $1262(44.4)$ & $0.72(0.66,0.78)$ & $<0.0001$ \\
\hline GOLD 2 & $1310(100.0)$ & $1293(100.0)$ & & \\
\hline SGRQ deterioration, trough $\mathrm{FEV}_{1}$ decline $\geq 100 \mathrm{~mL}$, moderate/severe exacerbation & $1053(80.4)$ & $1122(86.8)$ & $0.70(0.65,0.77)$ & $<0.0001$ \\
\hline Moderate/severe exacerbation & $780(59.5)$ & $835(64.6)$ & $0.83(0.75,0.92)$ & 0.0002 \\
\hline Trough FEV 1 decline $\geq 100 \mathrm{~mL}$ & $564(43.1)$ & $780(60.3)$ & $0.54(0.49,0.61)$ & $<0.0001$ \\
\hline SGRQ score increase $\geq 4$ units & $487(37.2)$ & $594(45.9)$ & $0.71(0.63,0.80)$ & $<0.0001$ \\
\hline GOLD 3 & $1239(100.0)$ & $1266(100.0)$ & & \\
\hline SGRQ deterioration, trough $\mathrm{FEV}_{1}$ decline $\geq 100 \mathrm{~mL}$, moderate/severe exacerbation & $1036(83.6)$ & $1091(86.2)$ & $0.69(0.63,0.75)$ & $<0.0001$ \\
\hline Moderate/severe exacerbation & $896(72.3)$ & $900(71.1)$ & $0.86(0.78,0.94)$ & 0.0010 \\
\hline Trough $\mathrm{FEV}_{1}$ decline $\geq 100 \mathrm{~mL}$ & $413(33.3)$ & $618(48.8)$ & $0.51(0.45,0.58)$ & $<0.0001$ \\
\hline SGRQ score increase $\geq 4$ units & $491(39.6)$ & $563(44.5)$ & $0.71(0.63,0.81)$ & $<0.0001$ \\
\hline GOLD 4 & $231(100.0)$ & $250(100.0)$ & & \\
\hline SGRQ deterioration, trough $\mathrm{FEV}_{1}$ decline $\geq 100 \mathrm{~mL}$, moderate/severe exacerbation & $197(85.3)$ & $191(76.4)$ & $0.90(0.74,1.10)$ & 0.3079 \\
\hline Moderate/severe exacerbation & $186(80.5)$ & $171(68.4)$ & $1.00(0.81,1.23)$ & 0.9798 \\
\hline Trough $\mathrm{FEV}_{1}$ decline $\geq 100 \mathrm{~mL}$ & $41(17.7)$ & $59(23.6)$ & $0.57(0.39,0.86)$ & 0.0066 \\
\hline SGRQ score increase $\geq 4$ units & $90(39.0)$ & $88(35.2)$ & $0.83(0.62,1.11)$ & 0.2105 \\
\hline
\end{tabular}

$\mathrm{Cl}$ confidence interval, CID clinically important deterioration, $F E V_{1}$ forced expiratory volume in $1 \mathrm{~s}, G O L D$ Global Initiative for Chronic Obstructive Lung Disease, $H R$ hazard ratio, SGRQ St. George's Respiratory Questionnaire

composite endpoint. The stepwise regression data also show that each component independently contributes to increased mortality risk. The composite endpoint is also sensitive to pharmacological treatment, and is similar to the findings of Singh et al., who observed a reduction in first CID with umeclidinium/vilanterol versus placebo in a post hoc study of the same composite endpoint [3]. Other post hoc analyses have used slightly different composite endpoints: $\mathrm{FEV}_{1}$, SGRQ and Transition Dyspnea Index focal score [6]; $\mathrm{FEV}_{1}$ or Transition Dyspnea Index; an increase in SGRQ; and a moderate-to-severe COPD exacerbation [4].

In all the publications that included $\mathrm{FEV}_{1}$, the strongest driver of CID in each of the analysis populations was lung function [3-6]. In contrast to these previous results, the most commonly reported endpoint in our study was exacerbations, perhaps because the UPLIFT study was 4 years long compared with the shorter (maximum 26 weeks) duration of the previous studies [3]. Our analysis showed a high overall frequency of CID for both treatment arms, which is expected due to the long study duration.
Lastly, we have shown that patients considered to have a CID early in the UPLIFT study (within the first 6 months) had worse outcomes for the 42-month remainder of the study; this was also confirmed in an analysis using CID as a time-varying covariate. These outcomes support results from previous analyses of the shorter TORCH and ECLIPSE studies. The 4-year length of our study provided valuable information on sustained CID and the relationship between clinically important events that could not be ascertained in clinical trials of shorter duration.

The study had limitations. In addition, relatively few patients with GOLD 4 lung function impairment were enrolled. Additionally, GOLD 4 patients have a lower baseline $\mathrm{FEV}_{1}$ than GOLD 2 or 3 patients, and as such, declines in $\mathrm{FEV}_{1}$ of $\geq 100 \mathrm{~mL}$ were less common, and would be expected to be more debilitating, in these patients. This should be considered in future studies, where percentage declines may be considered as an alternative clinically significant decline. The composite index considers the parameters SGRQ and moderate/severe exacerbations, which could be seen as subjective; 
Table 5 Risk of exacerbation or death from Month 6 onwards by CID status at Month 6 in the overall population and by GOLD

\begin{tabular}{|c|c|c|c|c|}
\hline $\begin{array}{l}\text { Outcome at } \\
\text { Month } 6\end{array}$ & $\begin{array}{l}\text { Patients with any CID } \\
\text { event vs. patients without, } \\
\text { HR ( } 95 \% \text { CI) }\end{array}$ & $\begin{array}{l}\text { Patients with confirmed FEV } \\
\text { decline vs. patients without, } \\
\text { HR }(95 \% \mathrm{Cl})\end{array}$ & $\begin{array}{l}\text { Patients with confirmed SGRQ } \\
\text { deterioration vs. patients without, } \\
\text { HR }(95 \% \mathrm{Cl})\end{array}$ & $\begin{array}{l}\text { Patients with moderate/severe } \\
\text { exacerbation vs. patients without, } \\
\text { HR ( } 95 \% \text { CI) }\end{array}$ \\
\hline \multicolumn{5}{|c|}{ Overall population } \\
\hline $\begin{array}{l}\text { Moderate/ } \\
\text { severe } \\
\text { exacerbation }\end{array}$ & $1.79(1.67,1.92)$ & $1.11(1.02,1.22)$ & $1.30(1.18,1.43)$ & $2.36(2.20,2.53)$ \\
\hline $\begin{array}{l}\text { Severe } \\
\text { exacerbation }\end{array}$ & $1.67(1.49,1.86)$ & $1.06(0.92,1.23)$ & $1.66(1.44,1.91)$ & $1.88(1.68,2.11)$ \\
\hline $\begin{array}{l}\text { Death up to } \\
\text { Day } 1470\end{array}$ & $1.21(1.06,1.39)$ & $1.09(0.92,1.31)$ & $1.27(1.05,1.54)$ & $1.22(1.05,1.41)$ \\
\hline \multicolumn{5}{|l|}{ GOLD 2} \\
\hline $\begin{array}{l}\text { Moderate/ } \\
\text { severe } \\
\text { exacerbation }\end{array}$ & $1.73(1.56,1.92)$ & $1.15(1.01,1.30)$ & $1.24(1.07,1.44)$ & $2.49(2.23,2.78)$ \\
\hline $\begin{array}{l}\text { Severe } \\
\text { exacerbation }\end{array}$ & $1.58(1.30,1.92)$ & $1.23(0.97,1.55)$ & $1.77(1.37,2.27)$ & $1.79(1.46,2.21)$ \\
\hline $\begin{array}{l}\text { Death up to } \\
\text { Day } 1470\end{array}$ & $1.21(0.95,1.55)$ & $1.26(0.94,1.68)$ & $1.36(0.98,1.90)$ & $1.01(0.75,1.35)$ \\
\hline \multicolumn{5}{|l|}{ GOLD 3} \\
\hline $\begin{array}{l}\text { Moderate/ } \\
\text { severe } \\
\text { exacerbation }\end{array}$ & $1.84(1.67,2.04)$ & $1.18(1.03,1.35)$ & $1.32(1.15,1.52)$ & $2.21(1.99,2.45)$ \\
\hline $\begin{array}{l}\text { Severe } \\
\text { exacerbation }\end{array}$ & $1.69(1.45,1.96)$ & $1.08(0.88,1.33)$ & $1.57(1.29,1.92)$ & $1.79(1.54,2.09)$ \\
\hline $\begin{array}{l}\text { Death up to } \\
\text { Day } 1470\end{array}$ & $1.20(0.99,1.45)$ & $1.17(0.91,1.51)$ & $1.30(1.00,1.70)$ & $1.15(0.94,1.41)$ \\
\hline \multicolumn{5}{|l|}{ GOLD 4} \\
\hline $\begin{array}{l}\text { Moderate/ } \\
\text { severe } \\
\text { exacerbation }\end{array}$ & $1.84(1.47,2.32)$ & $1.35(0.85,2.15)$ & $1.57(1.14,2.16)$ & $1.97(1.55,2.50)$ \\
\hline $\begin{array}{l}\text { Severe } \\
\text { exacerbation }\end{array}$ & $1.69(1.26,2.25)$ & $2.38(1.46,3.88)$ & $1.81(1.23,2.67)$ & $1.46(1.09,1.97)$ \\
\hline $\begin{array}{l}\text { Death up to } \\
\text { Day } 1470\end{array}$ & $1.16(0.84,1.60)$ & $1.52(0.88,2.63)$ & $1.00(0.60,1.66)$ & $1.22(0.87,1.70)$ \\
\hline
\end{tabular}

Time to death was calculated from Month 6 (180 days) to the date of death or the end of the vital status follow-up (Day 1470)

Cl confidence interval, CID clinically important deterioration, GOLD Global Initiative for Chronic Obstructive Lung Disease, HR hazard ratio, SGRQ St. George's

Respiratory Questionnaire

therefore, it is possible that this could introduce some variability in the results. Also, this was a post hoc analysis, although the large population and long follow-up time allowed for a satisfactory number of events to be observed.

\section{Conclusions}

We believe these results indicate that a composite endpoint of CID is a promising endpoint to assess disease activity in COPD clinical trials and may be a useful outcome that helps clinicians interpret the implications of trial results for individual patient management. Development of prospective studies is required to determine whether patients who experience disease progression (i.e. those who experience CID) at an increased rate can be identified earlier. By stratifying patients based on time to CID in a clinical trial database, it may be possible to identify characteristics that are associated with longer-term poor outcomes that could be useful for identifying which patients require further treatment earlier. Moreover, the composite endpoint may also serve to reduce patient numbers in clinical trials, as large numbers of patients are required to generate enough statistical power to detect a single outcome within patients with moderate COPD [18]. The length of trials may also be reduced, thereby limiting challenges such as patient discontinuation and cost that are prohibitive in trials of increased duration. Prospective studies are needed on the use of this concept to understand the sensitivity and efficacy of current and potential therapies. 


\section{Supplementary information}

Supplementary information accompanies this paper at https://doi.org/10. 1186/s12931-020-01431-y.

Additional file 1: Supplementary Table 1. Patients with $\mathrm{FEV}_{1}$ decline or SGRQ increase $6,12,18,24,30,36,42$, and 48 months after the first confirmed FEV 1 decline or SGRQ increase by GOLD 2, GOLD 3, and GOLD 4. Supplementary Table 2. Patients with $\mathrm{FEV}_{1}$ decline or SGRQ deterioration in the total UPLIFT population $6,12,18,24,30,36,42$, and 48 months after the initial unconfirmed $\mathrm{FEV}_{1}$ decline or SGRQ deterioration. Supplementary Table 3. Risk of exacerbation or death by unconfirmed clinically important deterioration status at Months 6 and 12 . Supplementary Table 4. Risk of exacerbation or death by confirmed clinically important deterioration status at Month 6 in the tiotropium and placebo arms, and at Month 12 in the tiotropium and placebo arms and total population. Supplementary Table 5. Risk of exacerbation or death by confirmed clinically important deterioration status calculated using clinically important deterioration event as a time-varying covariate. Supplementary Table 6. Patients with $\mathrm{FEV}_{1}$ decline or SGRQ deterioration in the total UPLIFT population $6,12,18,24,30,36$, and 42 months after the initial confirmed $\mathrm{FEV}_{1}$ decline or SGRQ deterioration: Tiotropium and placebo. Supplementary Table 7. Timing of FEV 1 decline and SGRQ deterioration relative to each other in the tiotropium and placebo arms. Supplementary Figure 1. Time to first event for (A) trough $\mathrm{FEV}_{1}$ decline $\geq 100 \mathrm{~mL}$, (B) SGRQ increase $\geq 4$ units and (C) moderate/severe exacerbation.

\section{Abbreviations}

Cl: Confidence interval; CID: Clinically important deterioration; COPD: Chronic obstructive pulmonary disease; FEV $_{1}$ : Forced expiratory volume in $1 \mathrm{~s}$; GOLD: Global Initiative for Chronic Obstructive Lung Disease; HR: Hazard ratio; SGRQ: St. George's Respiratory Questionnaire

\section{Acknowledgements}

The authors meet the criteria for authorship as recommended by the International Committee of Medical Journal Editors. They take full responsibility for the scope, direction, content of, and editorial decisions relating to, the manuscript, were involved at all stages of its development and have approved the submitted manuscript. The authors received no compensation related to the development of the manuscript. Medical writing assistance was provided by Laura Badtke of Complete HealthVizion and Claire Scofield of MediTech Media, which was contracted and compensated by Boehringer Ingelheim Pharma GmbH \& Co. KG. Dave Singh is supported by the National Institute for Health Research (NIHR) Manchester Biomedical Research Centre (BRC).

\section{Authors' contributions}

All the authors have made substantial contributions to the study design, data acquisition, analysis or interpretation, drafting the article, or critically revising the content. All authors provided final approval of the submitted version.

\section{Funding}

Supported by Boehringer Ingelheim Pharma GmbH \& Co. KG. Medical writing assistance was contracted and compensated by Boehringer Ingelheim Pharma GmbH \& Co. KG.

\section{Availability of data and materials}

Data are available from the corresponding author upon reasonable request.

\section{Ethics approval and consent to participate}

All studies included in this analysis were performed in accordance with the provisions of the Declaration of Helsinki (1996 version), in accordance with the International Conference on Harmonization Tripartite Guideline for Good Clinical Practice, and in accordance with applicable regulatory requirements and Boehringer Ingelheim Standard Operating Procedures. All patients provided written informed consent. This article does not report individual patient data; all data presented here are anonymised. The clinical tria protocols and the informed consent and patient information forms were reviewed and received approval/favourable opinion from a constituted local
Institutional Review Board or an Independent Ethics Committee at each centre prior to the start of the study.

\section{Competing interests}

K.F.R. reports personal fees from Boehringer Ingelheim, AstraZeneca, Novartis and Chiesi, and grants from Boehringer Ingelheim, AstraZeneca and Takeda, outside the submitted work. D.M.G.H. reports personal fees from AstraZeneca, Chiesi and Pfizer, and grants and personal fees from Boehringer Ingelheim, GlaxoSmithKline and Novartis, outside the submitted work. M.M. reports speaker fees from AstraZeneca, Boehringer Ingelheim, Chiesi, Cipla, Menarini, Rovi, Bial, Zambon, CSL Behring, Grifols and Novartis, and consulting fees from AstraZeneca, Boehringer Ingelheim, Chiesi,

GlaxoSmithKline, Bial, Gebro Pharma, CSL Behring, Laboratorios Esteve, Ferrer, Mereo Biopharma, Verona Pharma, TEVA, pH Pharma, Novartis and Grifols and research grants from GlaxoSmithKline and Grifols.

M.K.H. reports consultancy fees from Boehringer Ingelheim, GlaxoSmithKline, AstraZeneca and Mylan, speaker fees from Boehringer Ingelheim, and research support from Novartis Sunovion, outside the submitted work. F.J.M. reports grants from $\mathrm{NHLBI}$ during the conduct of the study, grants from the National Institutes of Health, personal fees from Continuing Education, Forest Laboratories, GlaxoSmithKline, Nycomed/Takeda, AstraZeneca, Boehringer Ingelheim, Bellerophon Therapeutics (formerly Ikaria), Genentech, Novartis, Pearl, Roche, Sunovion, Theravance, CME Incite, the Annenberg Center for Health Sciences at Eisenhower, Integritas, InThought, the National Association for Continuing Education, Paradigm Medical Communications, LLC, PeerVoice, UpToDate, Haymarket Communications, the Western Society of Allergy and Immunology, ProterixBio (formerly Bioscale), Unity Biotechnology, Concert Pharmaceuticals, Lucid, Methodist Hospital, Columbia University, Prime Healthcare Ltd., WebMD, PeerView Network, the California Society of Allergy and Immunology, Chiesi and the Puerto Rico Thoracic Society, and advisory board participation for Janssen, outside the submitted work. D.S. reports personal fees from Apellis, Cipla, Genentech, Peptinnovate and Skyepharma, and grants and personal fees from AstraZeneca, Boehringer Ingelheim, Chiesi, Glenmark, Merck, Mundipharma, Novartis, Pfizer, Pulmatrix, Teva, Theravance and Verona, outside the submitted work. L.G. was an employee of Boehringer Ingelheim at the time of the study and is now employed by CSL Behring. F.V. is an employee of Boehringer Ingelheim.

\section{Author details}

${ }^{1}$ Member of the German Center for Lung Research (DZL), LungClinic Grosshansdorf, Wöhrendamm 80, 22927 Grosshansdorf, Germany. ${ }^{2}$ Member of the German Center for Lung Research (DZL), Christian Albrechts University Kiel, Kiel, Germany. ${ }^{3}$ University of Exeter Medical School, College of Medicine and Health, University of Exeter, Exeter, UK. ${ }^{4}$ Division of Pulmonary and Critical Care, University of Michigan Health System, Ann Arbor, MI, USA. ${ }^{5}$ Pneumology Department, Hospital Universitari Vall d'Hebron, Vall d'Hebron Institut de Recerca (VHIR), Vall d'Hebron Barcelona Hospital Campus, Ciber de Enfermedades Respiratorias (CIBERES), Barcelona, Spain. ${ }^{6}$ Medicines Evaluation Unit (MEU), University of Manchester, Manchester University NHS Foundation Trust, Manchester, UK. ${ }^{7}$ Clinical Development, CSL Behring $\mathrm{GmbH}$, Marburg, Germany. ${ }^{8}$ Boehringer Ingelheim Pharma GmbH \& Co. KG, Ingelheim am Rhein, Germany. ${ }^{9}$ Department of Internal Medicine, Weill Cornell School of Medicine, New York, NY, USA.

Received: 7 November 2019 Accepted: 21 June 2020

Published online: 09 July 2020

\section{References}

1. Halpin DM, Tashkin DP. Defining disease modification in chronic obstructive pulmonary disease. COPD. 2009:6:211-25.

2. Tantucci C, Modina D. Lung function decline in COPD. Int J Chron Obstruct Pulmon Dis. 2012:7:95-9.

3. Singh D, Maleki-Yazdi MR, Tombs L, labal A, Fahy WA, Naya I. Prevention of clinically important deteriorations in COPD with umeclidinium/vilanterol. Int J Chron Obstruct Pulmon Dis. 2016:11:1413-24.

4. Anzueto AR, Vogelmeier CF, Kostikas K, Mezzi K, Fucile S, Bader G, Shen S, Banerji D, Fogel $R$. The effect of indacaterol/glycopyrronium versus tiotropium or salmeterol/fluticasone on the prevention of clinically important deterioration in COPD. Int J Chron Obstruct Pulmon Dis. 2017;12: 1325-37. 
5. Greulich T, Kostikas K, Gaga M, Aalamian-Mattheis M, Lossi NS, Patalano F, Nunez X, Pagano VA, Fogel R, Vogelmeier CF, Clemens A. Indacaterol/ glycopyrronium reduces the risk of clinically important deterioration after direct switch from baseline therapies in patients with moderate COPD: a post hoc analysis of the CRYSTAL study. Int I Chron Obstruct Pulmon Dis. 2018:13:1229-37.

6. Singh D, D'Urzo AD, Chuecos F, Munoz A, Garcia GE. Reduction in clinically important deterioration in chronic obstructive pulmonary disease with aclidinium/formoterol. Respir Res. 2017;18:106.

7. Martinez FJ, Lipworth BJ, Rabe KF, Collier DJ, Ferguson GT, Sethi S, Feldman GJ, O'Brien G, Jenkins M, Reisner C. Benefits of glycopyrrolate/formoterol fumarate metered dose inhaler (GFF MDI) in improving lung function and reducing exacerbations in patients with moderate-to-very severe COPD: a pooled analysis of the PINNACLE studies. Respir Res. 2020;21:128.

8. D'Urzo A, Bader G, Shen S, Goyal P, Altman P. Comparison of glycopyrronium versus tiotropium on the time to clinically important deteriorations in patients with COPD: a post-hoc analysis of randomized trials. NPJ Prim Care Respir Med. 2018;28:18.

9. Donohue JF. Minimal clinically important differences in COPD lung function. COPD. 2005;2:111-24.

10. Westwood M, Bourbeau J, Jones PW, Cerulli A, Capkun-Niggli G, Worthy G. Relationship between $\mathrm{FEV}_{1}$ change and patient-reported outcomes in randomised trials of inhaled bronchodilators for stable COPD: a systematic review. Respir Res. 2011;12:40

11. Cazzola M, MacNee W, Martinez FJ, Rabe KF, Franciosi LG, Barnes PJ, Brusasco V, Burge PS, Calverley PM, Celli BR, et al. Outcomes for COPD pharmacological trials: from lung function to biomarkers. Eur Respir J. 2008; 31:416-69.

12. Jones PW. Estimation and application of the minimum clinically important difference in COPD. Lancet Respir Med. 2014;2:167-9.

13. Decramer M, Celli B, Tashkin DP, Pauwels RA, Burkhart D, Cassino C, Kesten S. Clinical trial design considerations in assessing long-term functional impacts of tiotropium in COPD: the UPLIFT trial. COPD. 2004:1:303-12.

14. Tashkin DP. Celli B, Senn S, Burkhart D, Kesten S, Menjoge S, Decramer M, UPLIFT study investigators. A 4-year trial of tiotropium in chronic obstructive pulmonary disease. N Engl J Med. 2008;359:1543-54.

15. Global Initiative for Chronic Obstructive Lung Disease. Global strategy for the diagnosis, management and prevention of chronic obstructive pulmonary disease (2019 report). 2019. https://goldcopd.org/wp-content/ uploads/2018/11/GOLD-2019-v1.7-FINAL-14Nov2018-WMS.pdf. Accessed 7 Nov 2019.

16. Celli BR, Decramer M, Liu D, Metzdorf N, Asijee GM, Tashkin DP. Defining a COPD composite safety endpoint for demonstrating efficacy in clinical trials: results from the randomized, placebo-controlled UPLIFT ${ }^{\oplus}$ trial. Respir Res. 2016;17:48.

17. Celli BR, Decramer M, Asijee GM, Kupas K, Tashkin DP. Effects of tiotropium on exacerbations in patients with COPD with low or high risk of exacerbations: a post-hoc analysis from the 4-year UPLIFT ${ }^{\oplus}$ trial. Chronic Obstr Pulm Dis. 2015;2:122-30.

18. Freemantle N, Calvert M, Wood J, Eastaugh J, Griffin C. Composite outcomes in randomized trials: greater precision but with greater uncertainty? JAMA. 2003;289:2554-9.

\section{Publisher's Note}

Springer Nature remains neutral with regard to jurisdictional claims in published maps and institutional affiliations.

Ready to submit your research? Choose BMC and benefit from:

- fast, convenient online submission

- thorough peer review by experienced researchers in your field

- rapid publication on acceptance

- support for research data, including large and complex data types

- gold Open Access which fosters wider collaboration and increased citations

- maximum visibility for your research: over $100 \mathrm{M}$ website views per year

At $\mathrm{BMC}$, research is always in progress.

Learn more biomedcentral.com/submissions 